\title{
La Ghrelina, su relación con el odontoblasto.
}

\section{Fecha de Recepción}

19 de junio de 2014

\section{Aceptado para su publicación}

10 de septiembre de 2014
Silvia M. Segovia

Auxiliar Docente de Primera Categoría.

Cátedra Histología y Embriología.

Facultad de Odontología. U.N.N.E.

E-mail:smsegovia@odn.unne.edu.ar

Nathalie Enz

Jefe de Trabajos Prácticos. Cátedra Histología y Embriología. Facultad de Odontología. U.N.N.E.

E-mail:nenz@odn.unne.edu.ar

Bertha M. Valdovinos Zaputovich

Profesora Titular. Cátedra Histología y Embriología. Facultad de Odontología. U.N.N.E. E-mail: berthavz@el-litoral.com.ar

\section{Resumen}

La ghrelina péptido producido principalmente en estómago, ligando endógeno para receptor de secretagogos de hormona de crecimiento (GHS-R), relacionado con importantes acciones en el metabolismo energético, de papel relevante en la fisiología y fisiopatología de numerosos tejidos del organismo, cuya síntesis se relaciona con el aumento o disminución del apetito en estados de ayuno o ingesta de alimentos.

Se expresa en numerosos tejidos como los constituyentes del hipotálamo, hipófisis, placenta, páncreas, hígado, células hematopoyéticas, pulmón y en fluidos biológicos tales como sangre (hematíes), líquido cefalorraquídeo, leche y saliva.

Difundir el conocimiento actual de la presencia, función, acción e importancia de la ghrelina en los tejidos del organismo, destacando a los tejidos dentales, específicamente los odontoblastos del tejido pulpar podrían dimensionar su implicancia clínica odontológica.

\section{Palabras Claves}

Aparato digestivo. Tejido pulpar. Odontoblasto. Dentinogénesis. Orexia.

\section{Abstract}

Ghrelin peptide produced mainly in the stomach, the endogenous ligand for receptor growth hormone secretagogue (GHS-R), important actions related to energy metabolism, role in the 
REVISTA FACULTAD DE ODONTOLOGÍA

ISSN No 1668-7280 - Vol. VII № 1 - 2014

23
DIVULGACION

La Ghrelina, su relación con el

Odontoblasto. physiology and pathophysiology of many tissues of the body, whose synthesis is associated with increased or decreased appetite in fasted or food intake.

Is expressed in many tissues as constituents of the hypothalamus, pituitary, placenta, pancreas, liver, hematopoietic cells, lung, and in biological fluids such as blood cells (RBCs), cerebrospinal fluid, milk, and saliva.

Disseminate current knowledge of the presence, function, action and importance of ghrelin in body tissues, highlighting the dental tissues, specifically the odontoblasts of the pulp tissue could size your dental clinical implications.

\section{Keywords}

Digestive apparatus. Pulp tissue. Odontoblast. Dentinogenesis. Orexia.

\section{Resumo}

Péptido grelina produzida principalmente no estômago, o ligando endógeno para o receptor de secretagogo de hormona do crescimento (GHS-R), acções importantes relacionados com o metabolismo da energia, papel na fisiologia e patofisiologia de diversos tecidos do corpo, cuja síntese está associada com o aumento ou a diminuição do apetite na ingestão de comida ou em jejum.

É expresso em diversos tecidos, como componentes do hipotálamo, hipófise, placenta, pâncreas, fígado, células hematopoiéticas, pulmão, e em fluidos biológicos, tais como células do sangue (RBC), fluido cerebrospinal, leite e saliva.

Disseminar o conhecimento atual da presença, a função, a ação ea importância de grelina nos tecidos do corpo, com destaque para os tecidos dentais, especificamente os odontoblastos do tecido pulpar pode dimensionar sua implicação clínica dentária.

\section{Palavras chave}

Aparelho digestivo. Tecido pulpar. Eu odontoblastóides. Dentinogênese. Orexia.

\section{Introducción}

La ghrelina, cuya acción diana sobre células con receptores específicos del organismo (GHS-R) está vinculada con la ingestión de los alimentos y relacionada con el apetito aumenta en el plasma con el ayuno y se reduce con la ingesta de los mismos.

La administración experimental, con fines de investigación, de ghrelina en humanos y otros animales induce la sensación de apetito y/o hambre, cambio también observado en períodos de ayuno prolongado no experimental.

La existencia de cambios relevantes en los niveles plasmáticos asociados a la ingesta, parecen reafirmar la hipótesis de que la ghrelina circulante regula los mecanismos centrales relacionados con el apetito ubicados en el núcleo arqueado del hipotálamo. Se cree que el efecto orexigénico de la ghrelina puede estar parcialmente mediado por la actividad aferente del nervio vago'.

Hay evidencias de la acción reguladora de la ghrelina sobre la ingesta y la homeostasis energética, y un claro papel en las distintas alteraciones alimentarias como en el caso de la obesidad, la anorexia y la bulimia'. Estos niveles plasmáticos de ghrelina se han encontrado inversamente relacionados con el índice de masa corporal, observándose que aumentan después de la pérdida de peso inducida por restricción calórica ${ }^{2}$. En diversos estudios, en pacientes con anorexia nerviosa, se han encontrado niveles circulantes inicialmente elevados de ghrelina, los cuales se han normalizado si ocurre una recuperación de peso².

En roedores se ha observado que favorece la disminución en la utilización de ácidos grasos como sustrato energético y el aumento en la acumulación de grasa corporal, demostrando que los niveles circulantes de ghrelina dependen del estado energético del organismo.

\section{Desarrollo}

En humanos el gen que codifica la ghrelina se localiza en el cromosoma 3, en el locus 3p25-263 con un peso molecular 3,3I4 unidades de masa y un residuo de serina en posición 3 . En el plasma humano, el péptido sin modificar "des-acil-ghrelina" se encuentra en forma acilada en mayor porcentaje. Estudios recientes demuestran que esta forma puede unirse a partículas de lipoproteínas e intervenir en el transporte de lípidos ${ }^{3}$. 
La ghrelina se secreta de manera pulsátil y varía notablemente durante el día, con niveles pico precediendo a la ingesta de alimentos (preprandialmente) y descenso de las concentraciones circulantes de ghrelina luego de la ingesta de alimentos (postprandialmente).

Los niveles de ghrelina aumentan con el ayuno y decaen abruptamente 30 minutos después de comer, lo que sugiere que dicha hormona puede actuar como una señal para el inicio de la ingesta; dicha disminución es independiente del valor calórico del alimento ingerido ${ }^{4}$.

Bajo un régimen de alimentación con horarios fijos, la concentración de ghrelina circulante se incrementa justo antes de la hora de la ingesta del alimento y disminuye al finalizar la comida ${ }^{5}$. La ghrelina es la única hormona circulante, conocida en la actualidad, que promueve la ingesta después de su administración sistémica.

La cantidad de ghrelina durante el período fetal es muy baja en el estómago, incrementándose las concentraciones plasmáticas de ghrelina en el período posnatal en forma paralela con la cantidad de ghrelina que produce el estómago 3 .

Se expresa ampliamente en todo el organismo, estando implicada en varias funciones metabólicas fisiológicas, tales como: de la glucosa, del balance de energía, de motilidad gastrointestinal, de secreción de ácido gástrico y pancreática, así como del sistema inmune, cardiovascular, óseo y de proliferación y supervivencia celular. Se la ha relacionado también influenciando la memoria, el sueño y el aprendizaje ${ }^{4}$.

La acción de la ghrelina tiene un efecto rápido en el organismo, expresado por unas ganas incontroladas de ingerir alimento. En humanos, la administración intravenosa experimental de la misma aumenta el apetito y estimula la ingesta alimentaria $^{5}$. Además de estos efectos estimulantes sobre la ingesta de alimentos en los seres humanos y roedores, la ghrelina también estimula la ganancia de peso corporal a través de un aumento de la adipogénesis.

Los niveles de ghrelina se encuentran alterados en pacientes obesos y en aquellas que han sufrido una importante pérdida de peso corporal, lo que lleva a pensar que esta hormona podría tener un papel importante como señal indicadora de deficiencia energética. Estudios iniciales han demostrado cómo los niveles plasmáticos bajos de ghrelina están correlacionados negativamente con el porcentaje elevado de grasa y peso corporal'. Tras una pérdida de peso inducida por dieta los niveles plasmáticos de ghrelina se incrementan significativamente, sugiriendo la existencia de un efecto rebote en ganancia de peso, después de la finalización de la dieta.

Numerosos trabajos científicos sobre el tema han postulado la función y el posible papel de esta sustancia en el origen, relación y tratamientode trastornos alimentarios, como la obesidad y la anorexia. En pacientes obesos los niveles plasmáticos de ghrelina son bajos y están asociados, generalmente, con un incremento de peso. En pacientes adultos, con síndrome de Prader-Willi (obesidad genética, caracterizados por la hiperfagia), existe un incremento muy marcado de los niveles plasmáticos de ghrelina comparado con sujetos delgados y obesos.

En caso de estados de malnutrición, como la anorexia y caquexia, los niveles plasmáticos de ghrelina se encuentran muy elevados. En la anorexia nerviosa se ha comprobado como la recuperación de peso normaliza los niveles plasmáticos de ghrelina, hasta valores idénticos a los obtenidos en sujetos normales'.

Como ya se ha dicho anteriormente, la ghrelina es una hormona que varía de forma importante dependiendo del estado nutricional del individuo. Asimismo, la ingesta de nutrientes provoca una caída en los niveles circulantes de ghrelina.

Actualmente se acepta que tanto la insulina como la glucosa tienen un efecto inhibitorio sobre los niveles de ghrelina; la administración tanto oral como intravenosa de glucosa disminuye los niveles de ghrelina.

Investigaciones recientes señalan un potencial papel regulador de la ghrelina sobre el sistema inmune, modulando la proliferación de células $T$ y la producción de citosinas a partir de células $T$ activadas. Por lo tanto la ghrelina puede funcionar como un modulador importante no sólo para el sistema endocrino, sino también para el sistema inmunológico ${ }^{6}$.

Se ha detectado la expresión de ghrelina a nivel de los tejidos dentarios, principalmente en los odontoblastos de la pulpa dentaria. Células altamente especializadas, específicas del tejido 
pulpar, cuya función es la formación de la dentina $^{7,8}$. El tejido pulpar y dentinario conforman una unidad biológica denominada complejo dentino-pulpar, destacando que ambos tejidos comparten un origen embrionario común (ectomesénquima que forma la papila del gérmen dentario) $)^{7,8}$.

La dentina formada durante el desarrollo dentario hasta la completa formación de la raíz, se denomina dentina primaria y comprende la dentina del manto y la dentina circumpulpar. La dentina sintetizada de forma fisiológica después de la formación de la raíz recibe el nombre de dentina secundaria, siendo el resultado de la función secretora de los odontoblastos una vez terminado el desarrollo dentario. La formación de dentina secundaria tiene lugar durante toda la vida del diente ${ }^{7,9}$.

La presencia de ghrelina en las células odontogénicas de la pulpa fue demostrada mediante la técnica de inmunohistoquímica, utilizando un anticuerpo anti-ghrelina ${ }^{10}$.

Los odontoblastos secretan varias proteínas colágenas y no colágenas para formar una matriz extracelular única. Colágeno tipo I, proteoglicanosy sialofosfoproteína dentinaria, se encuentran entre las moléculas sintetizadas y secretadas por los odontoblastos 7,8 .

Es posible que la ghrelina actúe en los odontoblastos jugando un papel destacado en la dentinogénesis y en el proceso de mineralización.

La neoformación dentinaria es dependiente de la actividad odontoblástica, el ectomesénquima pulpar posee cierta capacidad de autodiferenciación en tejido odontogénico. En una pulpa joven los odontoblastos adoptan disposición en empalizada (epitelio pseudoestratificado) ${ }^{7,8,11}$.

Los odontoblastos son considerados como "células posmitóticas fijas", altamente diferenciadas que han perdido la capacidad de dividirse y deben ser reemplazados por células subyacentes mesenquimatosas indiferenciadas, que maduran, a partir de precursores indiferenciados en división o mediante rediferenciación de los fibroblastos. Se requiere un tiempo para la proliferación y diferenciación de los nuevos odontoblastos de reemplazo. Los fibroblastos pulpares parecen sufrir desdiferenciación para volver a ser células mesenquimáticas indiferenciadas ${ }^{\prime \prime}$.
La actividad funcional del tejido dentario consiste en actuar como soporte mecánico en la actividad masticatoria normal de las estructuras dentarias y también en la homeostasis del organismo, ya que la misma se encuentra relacionada con la proliferacion celular y con la participación, por sus características estructurales y biológicas, en la defensa y sensibilidad del complejo dentino pulpar.

Los odontoblastos persisten en la pulpa y mantienen su capacidad dentinogénica durante toda la vida de la pieza dentaria del individuo, dotando al complejo dentino-pulpar de capacidad de respuesta frente a diferentes agentes agresivos o noxas.

La ghrelina procedente quizás de las piezas dentarias podría estar implicada en la estimulación de los centros de alimentación, de manera similar a la ghrelina liberada por la mucosa gástrica $^{10}$.

En relación a estudios científicos publicados, que presumen que la ghrelina pulpar probablemente se originaría a partir de los odontoblastos o de los vasos sanguíneos de la pulpa dentaria; se está llevando actualmente una investigación en nuestra unidad académica, destacando la importancia metabólica fisiológica de la ghrelina, péptido residual formado por 28 aminoácidos, producido principalmente por las células fúndicas del estómago, transportada por el torrente sanguíneo, ligada a lipoproteínas de alta densidad y posiblemente a albúmina ${ }^{4}$, presente en casi todos los tejidos humanos incluyendo a las piezas dentarias. Cuya expresión y patrón de distribución pretendemos demostrar y convalidar utilizando la técnica de Inmunohistoquimica. Otros reportes científicos consultados referidos al tema, destacan un punto que interpretamos de vital importancia en relación a la función fisiológica de la ghrelina; que es la relacionada con la proliferación y supervivencia celular ${ }^{4}$, que de demostrar nosotros su expresión y patrón de distribución, nos llevaría a plantear una hipótesis, situándola como posible factor inductor, de formación o crecimiento en relación a la dentina (dentinogénesis), a lo largo de la vida de la pieza dentaria temporaria o permanente, relacionado esto a las funciones hipotalámicas básicas de supervivencia del hombre o animal. 


\section{Conclusión}

En razón de lo expuesto, se reconoce que la ghrelina es una hormona de secreción predominantemente gástrica/neuropéptido, que se destaca por su acción en la regulación de la saciedad, peso corporal, indicador de insuficiencia energética, y procesos fisiopatológicos. Por lo que, conocer sus mecanismos íntimos de acción puede permitirnos el entendimiento de la biología química del eje gástrico hipotalámicohipofisario y sus posibles efectos biológicos en piezas dentarias de humanos y otros animales.

Siendo conscientes que actualmente no existen suficientes conocimientos científicos que puedan confirmar o descartar la producción de ghrelina en la pulpa así como su acción en la misma, interpretamos hace falta por lo tanto profundizar en las investigaciones y publicaciones que conduzcan a un mayor conocimiento $y$ difusión acerca de la misma.

\section{Bibliografía}

I. Seoane LM, Lage M, Al-Massadi O, Diéguez C, Casanueva FF. Papel de la Ghrelina en la fisiopatología del comportamiento alimentario. Rev. Med. Univ. 2004. VOL 48(N 2); II - I7.

2. Del Rincón Carero JP. Ghrelina un péptido modulador del metabolismo energético. Revista de Endocrinología y Nutrición. 2007. Vol. 15 (No3); I38-I 48.

3. Nahum Méndez-Sánchez, Norberto C ChávezTapia y Misael Uribe-Esquivel. La ghrelina y su importancia con el eje gastrohipotalámico. Gac. Méd. Méx. Vol. I42, N I México ene./feb. 2006.

4. Morgado Viveros E, Caba Vinagre MS. Grelina: Una hormona reguladora de la ingesta de alimento y del peso corporal. Rev. Med. UV: 2008; Vol. 8, N². 35-40.

5. Tucci S A. Grelina en regulación del apetito y papel en obesidad y trastornos alimentarios: Abordajes terapéuticos. Rev. Venez Endocrinol; 2008; 6(2); 15-23.

6. K Ohta, NJ Laborde, M Kajiya I, J Shin, T Zhu AK Thondukolam, C Min, N Kamata, NY Karimbux, $\mathrm{P}$ Stashenko4, and $\mathrm{T}$ Kawail. Expres- sion and Possible Immune-regulatory Functionof Ghrelin in Oral Epithelium. J Dent Res 90(II): 1286-1292, 20II.

7. Gómez de Ferraris ME, Campos Muñoz A. Histología, Embriología e Ingeniería Tisular Bucodental. 3 ed. Editorial Médica Panamericana. 2009.

8. Valdovinos Zaputovich B y col. Manual Texto Atlas Histología y Embriología. 3ra. ed. Facultad de Odontología. UNNE. 2012.

9. Castellanos-Cosano L, Martín-González C, López-Frías FJ, Velasco-Ortega JM, Segura-Egea J. J. Endodoncia preventiva: Protección pulpar mediante la técnica de eliminación de la caries en etapas. Odontoestomatol. Vol. 27. $\mathrm{N}^{\circ} 5$. Madrid. Set-oct.20II.

10. Uleyman Aydin, Hanefi Ozercan I brahim, Hikmet Geckil, Ferda Dagli, Suna Aydin, Sinem Kumru, Nermin Kilic, Brahim Sahin, Mehmet Resat Ozercan. La ghrelina está presente en los dientes. Journal of Biochemistry and Molecular Biology. Vol.40, N 3. Mayo 2007. Pp 368-372.

II. Roig A, Henríquez J, Alvear M, Salazar LA. Análisis Morfométrico del número de odontoblastos en recubrimientos directos con hidróxido de calcio y propóleos en canes. Int. J. Morphol. 29(3):799-805, 2011.

12. Verhulst PJ, Depoortere I, World J. La grelina segunda vida: De estimulador del apetito al regulador de la glucosa. Gastroenterología. 2012; I8(25); 3183-95.

13. Al-Massadi Iglesias O. Regulación de la secreción gástrica de ghrelina, acción hormonal, control neuroendocrino y desarrollo postnatal. Diciembre 2009.

14. Rodríguez Palomo D, Alfaro Benavides A. Actualización de la fisiología gástrica. Medicina Legal de Costa Rica. Vol. 27 (2), setiembre 2010. 59-68.

15. Orban B. Histología y Embriología Bucal. 4ta ed. México: Editorial La Prensa Médica Mexicana. 1980.

16. Avery JK, Chiego DJ Jr. Principios de Histología y Embriología Bucal con orientación clínica. $3^{\circ} \mathrm{ed}$. Editorial Elsevier. Madrid, España. 2002.

17. D Silva Herzog Flores, R Oliva, PC Ramos Núñez. Mecanismo de presentación antigénica en el tejido pulpar. Vol. LXII, No. 4Julio-Agosto 2005pp |25-|3|.

18. Horvarth TL, Diano S, Sotonyi P, Helman M, Tschop M, Minereview. Ghrelin and regulation of energy balance a hypothalamic perspective. Endocrinology 200I, I42, 4-1639. 